\title{
Article \\ The Improvement of Air Quality and Associated Mortality during the COVID-19 Lockdown in One Megacity of China: An Empirical Strategy
}

\author{
Zhihu Xu (D), Ru Cao, Xin Hu, Wenxing Han, Yuxin Wang, Jing Huang and Guoxing Li *(D) \\ Department of Occupational and Environmental Health Sciences, Peking University School of Public Health, \\ 38 Xueyuan Road, Haidian District, Beijing 100191, China; zhihu_xu@sina.com (Z.X.); \\ 13051555836@163.com (R.C.); xqxieqianqx@126.com (X.H.); hhwwxx499@163.com (W.H.); \\ yuxin_wang@bjmu.edu.cn (Y.W.); jing_huang@bjmu.edu.cn (J.H.) \\ * Correspondence: liguoxing@bjmu.edu.cn; Tel.: +86-10-8280-1522
}

Citation: Xu, Z.; Cao, R.; Hu, X.; Han, W.; Wang, Y.; Huang, J.; Li, G. The Improvement of Air Quality and Associated Mortality during the COVID-19 Lockdown in One Megacity of China: An Empirical Strategy. Int. J. Environ. Res. Public Health 2021, 18, 8702. https:// doi.org/10.3390/ijerph18168702

Academic Editors: Paul

B. Tchounwou and Jeanine M. Buchanich

Received: 10 June 2021

Accepted: 14 August 2021

Published: 18 August 2021

Publisher's Note: MDPI stays neutral with regard to jurisdictional claims in published maps and institutional affiliations.

Copyright: (c) 2021 by the authors. Licensee MDPI, Basel, Switzerland. This article is an open access article distributed under the terms and conditions of the Creative Commons Attribution (CC BY) license (https:/ / creativecommons.org/licenses/by/ $4.0 /)$.

Abstract: Although the lockdown policy implemented during the COVID-19 pandemic indeed improved the air quality and reduced the related health risks, the real effects of the lockdown and its resulting health risks remain unclear considering the effects of unobserved confounders and the longstanding efforts of the government regarding air pollution. We compared air pollution between the lockdown period and the period before the lockdown using a difference-in-differences (DID) model and estimated the mortality burden caused by the number of deaths related to air pollution changes. The $\mathrm{NO}_{2}$ and $\mathrm{CO}$ concentrations during the lockdown period (17 days) declined by $8.94 \mu \mathrm{g} / \mathrm{m}^{3}$ (relative change: $16.94 \%$; $95 \% \mathrm{CI}: 3.71,14.16$ ) and $0.20 \mathrm{mg} / \mathrm{m}^{3}$ (relative change: $16.95 \%$; $95 \%$ CI: $0.04,0.35$ ) on an average day, respectively, and $\mathrm{O}_{3}$ increased by $8.41 \mu \mathrm{g} / \mathrm{m}^{3}$ (relative change: $32.80 \%$; $95 \%$ CI: 4.39, 12.43); no meaningful impacts of the lockdown policy on the $\mathrm{PM}_{2.5}, \mathrm{PM}_{10}, \mathrm{SO}_{2}$, or the AQI values were observed. Based on the three clearly changed air pollutants, the lockdown policy prevented 8.22 (95\% CI: 3.97, 12.49) all-cause deaths. Our findings suggest that the overall excess deaths caused by air pollution during the lockdown period declined. It is beneficial for human health when strict control measures, such as upgrading industry structure and promoting green transportation, are taken to reduce emissions, especially in cities with serious air pollution in China, such as Shijiazhuang.

Keywords: lockdown policy; air pollution; difference-in-differences; health risk

\section{Introduction}

The severe acute respiratory syndrome-coronavirus 2 (SARS-CoV-2) pandemic identified in 2019 (COVID-19) was reported to have caused 144,358,956 confirmed cases of coronavirus disease worldwide by 24 April 2021 [1]. The pandemic has changed almost every aspect of life worldwide. As asymptomatic infections play an important role in the spread of COVID-19 [2], many countries have adopted a series of restrictive measures to address the spread of the virus by implementing lockdown policies such as closing schools, workplaces, and public transport.

Some good news about the COVID-19 pandemic is that it has been reported that lockdown policies have positive implications for the environment. The air quality parameters of $\mathrm{PM}_{2.5}, \mathrm{PM}_{10}, \mathrm{NO}_{\mathrm{x}}, \mathrm{CO}$, and $\mathrm{SO}_{2}$ improved in many parts of the world during the lockdown period [3-5]. However, the concentrations of $\mathrm{O}_{3}$ were reported to have increased during the same period $[3,5,6]$. Lockdown policies have provided an opportunity to quantitatively evaluate the public health impacts resulting from resisting public transportation, closing factories, and balancing health and financial losses.

Although previous studies have shown improvements in air pollution during the lockdown period, these changes measured during the lockdown period could not represent 
the effect of the lockdown well because of confounders such as secular trends and weather influences [7,8]. Previous studies have assessed the health effects associated with air pollution during the Asia-Pacific Economic Cooperation (APEC) [9] and the 2015 China large-scale military parade periods [10], and one possible problem faced in these studies, as well as recent studies [11,12] during COVID, is a bias against the real effects of policies on air pollutants. The difference-in-differences (DID) model has been widely used to evaluate given interventions. A previous study applied a self-control DID method to evaluate the changes of air pollutants during the lockdown period [13]. This study tentatively used a DID analysis as an empirical strategy to explore the causal impacts of the lockdown policy on air pollutants; this analysis allowed us to control for omitted variables. We used the DID estimation technique to evaluate six air pollutants and the AQI during the lockdown period. To the best of our knowledge, this is the first study to use a case-control DID evaluation to calculate the health risks related to policy effects.

An outbreak of the COVID-19 pandemic occurred in Shijiazhuang, China, in January of 2021, and Shijiazhuang strictly implemented a city lockdown policy from 6 January [14] until 23 January [15]; this policy included closing workplaces, public transport and external transport with other cities, restricting gatherings, etc. This study assessed the changes in air pollution and related health risks that occurred during the lockdown period in Shijiazhuang based on a DID method.

\section{Materials and Methods}

\subsection{Site Information of Air Pollutant Concentrations}

Shijiazhuang and Baoding are relatively close in space. According to the statistical yearbooks of the two cities, the energy consumption patterns and high-emission industries shared similar levels between two cities, making these cities suitable for comparison. Based on the two reasons above, we finally chose Baoding as the control group in the DID model. There were eight air pollution monitoring sites in Shijiazhuang and six air pollution monitoring sites in Baoding; these sites were updated hourly.

\subsection{Air Pollution and Weather Data}

The city-level daily concentrations of six pollutants $\left(\mathrm{SO}_{2}, \mathrm{NO}_{2}, \mathrm{CO}, \mathrm{PM}_{10}, \mathrm{PM}_{2.5}\right.$, and $\mathrm{O}_{3}$ ) and the AQI for Shijiazhuang and Baoding of Hebei Province of China were collected from the daily air quality readings of the China National Environmental Monitoring Centre (CNEMC), obtained from local monitoring stations from December 20, 2020, to January 22, 2021. Since changes in pollutants are also often controlled by meteorological conditions [16], daily weather variables, including the daily average temperature, mean relative https: / / www.ogimet.com [humidity, and daily average wind speed, were also added to the model as covariables for analysis. Although precipitation removes air pollutants, no precipitation occurred in either city, and precipitation was not included in the analysis. All meteorological data were downloaded from the Synop stations and are available at accessd on 25 February 2021].

We compared the daily mean concentrations of six pollutants and the AQI values in different periods of lockdown (before and during) using the Wilcoxon test due to the non-normal distribution of pollutant data.

\subsection{Baseline Number of Outcome Events}

We assumed that the size of the baseline population changed minimally during the lockdown period. According to the Statistical Bulletin of National Economic and Social Development of Shijiazhuang [17], there were 10.39 million residents in Shijiazhuang at the time this study was performed. Based on an overall annual mortality rate of 5.2 individuals per thousand, the daily mortality count would be 148. According to a previous study [18], among the overall mortalities, the proportions of cardiovascular mortality and respiratory mortality were $43.74 \%$ and $12.32 \%$, respectively, so it was estimated that there were approx- 
imately 65 and 18 deaths from cardiovascular and respiratory diseases, respectively, each day in Shijiazhuang.

\subsection{DID Model}

Although there have been many studies indicating the association of city lockdowns with improved air pollution, a key challenge is the endogeneity of city lockdowns originating from various confounding factors that potentially affect air pollution. One confounding factor is that the government has expended efforts to protect the environment, so the impact of the lockdown policy would be overestimated if we directly compared the two periods before and after the lockdown. To explore the realistic effect of the lockdown policy, we employed DID models. The DID models allowed us to control for various confounding factors and to identify the potential causal impacts of lockdown measures. Cities without lockdown policies, such as Baoding, can serve as counterfactuals and provide a reference level with which to study Shijiazhuang. We estimated the relative changes in air pollution levels between Shijiazhuang and Baoding using the following model (1):

$$
\mathrm{Y}_{\mathrm{i}, \mathrm{t}}=\beta \times \text { lockdown }_{\mathrm{i}, \mathrm{t}}+\alpha \times \mathrm{Z}_{\mathrm{i}, \mathrm{t}}+u_{\mathrm{i}}+v_{\mathrm{t}}+\varepsilon_{i, t}
$$

where $Y_{i, t}$ represents the level of air pollution in city i on date $t$; lockdown $n_{i, t}$ denotes whether a lockdown is enforced in city $i$ on date $t$ and takes the value of 1 if the city is locked down; $Z_{i, t}$ are the control variables, including the daily average temperature, mean relative humidity, and daily average wind speed; $u_{\mathrm{i}}$ indicates city fixed effects; $v_{\mathrm{t}}$ indicates date fixed effects; $\varepsilon_{i, t}$ is a disturbance term; $\alpha$ and $\beta$ are the response parameters of the dependent variable.

We explored the effects of the lockdown policy using this DID model and evaluated the all-cause, cardiovascular, and respiratory disease deaths attributed to three distinct variations in pollutants.

\subsection{Estimation of the Mortality Effects of a Unit Change in Daily Pollutant Concentrations}

Previous studies have reported that the relationship between air pollutants and mortality is approximately linear without obvious threshold $[19,20]$. The exposure-response relationship is widely used to evaluate the health impact by many researchers [9,21]. In this study, the health impact assessment was conducted based on the exposure-response function and relevant baseline data about population size, baseline mortality, and changes in air pollution concentrations after calculating from the DID model. The numbers of avoided or increased deaths were attributed to the changes in pollutant concentrations based on the following formulas:

$$
\begin{gathered}
\Delta_{\text {number_of_mortality }}=\text { baseline_mortality } \times \beta \times \Delta P C \\
\Delta_{\text {lower_limit_number_of_mortality }}=\text { baseline_mortality } \times \beta_{\text {lower }} \times \Delta P C \\
\Delta_{\text {upper_limit_number_of_mortality }}=\text { baseline_mortality } \times \beta_{\text {upper }} \times \Delta P C
\end{gathered}
$$

where $\Delta$ number_of_mortality is the estimated change in the number of deaths, $\beta$ is the coefficient of the exposure-response function associated with daily pollutant concentration (per $1 \mu \mathrm{g} / \mathrm{m}^{3}$ change) and mortality, and $\triangle P C$ is the change in ambient pollutant concentrations.

To better evaluate the short-term health effects of air pollutants, we preferentially integrated the domestic studies as $\beta[9,22-24]$ considering the susceptibility in different populations.

We obtained the all-cause mortality excess risk, cardiovascular mortality, and respiratory mortality from previously published time-series studies conducted in China on the three main kinds of pollutants $\left(\mathrm{NO}_{2}, \mathrm{CO}, \mathrm{O}_{3}\right)$; these pollutants were confirmed to significantly change through the DID process. According to a previous study [22], a $10 \mu \mathrm{g} / \mathrm{m}^{3}$ increase in the daily $\mathrm{NO}_{2}$ concentration in China would lead to a $0.65 \%$ (95\% CI: $0.50 \%$, $0.80 \%$ ) increase in all-cause mortality, a $0.60 \%$ (95\% CI: $0.41 \%, 0.79 \%)$ increase in cardiovascular mortality, and a $0.73 \%(95 \% \mathrm{CI}: 0.46 \%, 1.00 \%)$ increase in respiratory mortality. Another study [18] of $\mathrm{NO}_{2}$ and linked mortality in China came up with some estimations 
and related health assessment could be found in supplement material. The estimates of the short-term associations among $\mathrm{O}_{3}, \mathrm{CO}$, and all-cause, cardiovascular, and respiratory disease-related mortality are shown in Table 1.

Table 1. The association between daily $\mathrm{NO}_{2}, \mathrm{CO}$, and $\mathrm{O}_{3}$ concentrations and mortality obtained from previous studies in China.

\begin{tabular}{|c|c|c|c|c|c|}
\hline & Study & Study Period & Daily Increment & Death Cause & $\beta^{a}(95 \% C I)$ \\
\hline $\mathrm{NO}_{2}{ }^{\mathrm{b}}$ & Li, 2021 [23] & 2013-2017 & $10 \mathrm{ug} / \mathrm{m}^{3}$ & $\begin{array}{l}\text { All-cause mortality } \\
\text { CVD mortality } \\
\text { Respiratory mortality }\end{array}$ & $\begin{array}{l}0.65 \%(0.50 \%, 0.80 \%) \\
0.60 \%(0.41 \%, 0.79 \%) \\
0.73 \%(0.46 \%, 1.00 \%)\end{array}$ \\
\hline $\mathrm{CO}$ & Liu, 2018 [18] & 2013-2015 & $1 \mathrm{mg} / \mathrm{m}^{3}$ & $\begin{array}{l}\text { All-cause mortality } \\
\text { CVD mortality } \\
\text { Respiratory mortality }\end{array}$ & $\begin{array}{c}\mathrm{NA} \\
1.12 \%(0.42 \%, 1.83 \%) \\
\mathrm{NA}\end{array}$ \\
\hline $\mathrm{O}_{3}$ & Yan, 2013 [24] & meta-analysis & $10 \mathrm{ug} / \mathrm{m}^{3}$ & $\begin{array}{l}\text { All-cause mortality } \\
\text { CVD mortality } \\
\text { Respiratory mortality }\end{array}$ & $\begin{array}{l}0.42 \%(0.32 \%, 0.52 \%) \\
0.44 \%(0.17 \%, 0.70 \%) \\
0.50 \%(0.22 \%, 0.77 \%)\end{array}$ \\
\hline
\end{tabular}

a $\beta$ and its 95\% CI refer to coefficients and corresponding 95\% CI for the association between daily increment of air pollutants and mortality.

b Chen et al. [24] reported association between $\mathrm{NO}_{2}$ and related mortality in 2018 as well; related health impact assessment can be found in Supplementary Material Table S1.

\subsection{Sensitivity Analysis}

To test the validity of the DID estimate, we randomly moved up the time at which the lockdown policy was implemented in Shijiazhuang and checked if the coefficient estimate was significant.

All data analyses were conducted by R software (version 4.0.1, RStudio Team, Boston, MA, USA), the DID model was built by the "plm" package, and the level of significance was defined as $p<0.05$ (two-tailed).

\section{Results}

\subsection{Comparisons of Air Pollution Concentrations in Different Periods}

After calculating the median and IQR concentrations of the AQI and pollutants, which are shown in Table 2, significant changes $(p<0.05)$ in $\mathrm{NO}_{2}, \mathrm{O}_{3}$, and $\mathrm{SO}_{2}$ were found in both Shijiazhuang and Baoding. The median concentration of $\mathrm{NO}_{2}$ was $21.90(\mathrm{IQR}=12.99)$ $\mu \mathrm{g} / \mathrm{m}^{3}$ during the lockdown days, while the median concentration of $\mathrm{NO}_{2}$ before the lockdown in Shijiazhuang was $55.01(\mathrm{IQR}=26.48) \mu \mathrm{g} / \mathrm{m}^{3}$. Although $\mathrm{NO}_{2}$ decreased in both Shijiazhuang and Baoding during the lockdown period, it seems that the decline in Shijiazhuang was even greater than that in Baoding. $\mathrm{SO}_{2}$ showed the same behavior as $\mathrm{NO}_{2} . \mathrm{O}_{3}$ increased in both cities during the lockdown time. In contrast, $\mathrm{CO}$ in Shijiazhuang decreased significantly compared to that in Baoding.

\subsection{DID Results}

When controlling for weather variables (temperature, relative humidity, and wind speed), individual fixed effects, and time fixed effects, we estimated the relative changes in air pollutants and the AQI in Shijiazhuang relative to those in Baoding by fitting the DID model (Table 3). We found that the lockdown policy did improve the $\mathrm{NO}_{2}$ and $\mathrm{CO}$ situations, and the daily $\mathrm{NO}_{2}$ and $\mathrm{CO}$ declined by $8.94 \mu \mathrm{g} / \mathrm{m}^{3}(95 \% \mathrm{CI}: 3.71,14.16)$ and $0.2 \mathrm{mg} / \mathrm{m}^{3}$ (95\% CI: 0.04, 0.35), respectively, when weather controls and fixed effects were included, indicating that those associated with the city lockdown were unlikely to be caused by weather or natural trends. The daily relative changes of $\mathrm{NO}_{2}$ and $\mathrm{CO}$ were $16.94 \%$ and $16.95 \%$. The parameters of $\mathrm{PM}_{10}, \mathrm{PM}_{2.5}$, and the $\mathrm{AQI}$ were greater than zero but with no significance, indicating that no significant change occurred during the lockdown period. The daily concentration of $\mathrm{O}_{3}$ significantly increased by $8.41 \mu \mathrm{g} / \mathrm{m}^{3}$ (95\% CI: 4.39, $12.43)$, with a $32.80 \%$ daily relative change. 
Table 2. Summary statistics of the AQI and pollutants from 20 December 2020 to 22 January 2021.

\begin{tabular}{|c|c|c|c|c|c|c|}
\hline \multirow[b]{2}{*}{ Shijiazhuang } & \multicolumn{2}{|c|}{20 December 2020-5 January $2021^{a}$} & \multicolumn{3}{|c|}{6 January 2021-22 January $2021^{a}$} & \multirow[b]{2}{*}{$p$-Value } \\
\hline & Median & IQR & Median & IQR & $W^{\mathbf{b}}$ & \\
\hline AQI & 81.06 & 35.01 & 87.47 & 75.33 & 139 & 0.865 \\
\hline $\mathrm{CO}$ & 1.23 & 0.83 & 0.60 & 0.42 & 216 & 0.013 \\
\hline $\mathrm{NO}_{2}$ & 55.01 & 26.48 & 21.90 & 12.99 & 246 & 0.000 \\
\hline $\mathrm{O}_{3}$ & 22.26 & 14.14 & 44.78 & 19.63 & 39 & 0.000 \\
\hline $\mathrm{PM}_{10}$ & 105.26 & 53.32 & 108.40 & 118.82 & 132 & 0.683 \\
\hline $\mathrm{PM}_{2.5}$ & 54.00 & 39.85 & 41.78 & 49.82 & 161 & 0.586 \\
\hline $\mathrm{SO}_{2}$ & 20.66 & 11.29 & 12.19 & 5.77 & 212 & 0.020 \\
\hline \multicolumn{7}{|l|}{ Baoding } \\
\hline AQI & 79.60 & 42.62 & 75.14 & 62.72 & 152 & 0.812 \\
\hline $\mathrm{CO}$ & 0.95 & 0.70 & 0.70 & 0.39 & 194 & 0.092 \\
\hline $\mathrm{NO}_{2}$ & 61.64 & 20.40 & 42.33 & 21.45 & 224 & 0.005 \\
\hline $\mathrm{O}_{3}$ & 13.90 & 15.15 & 25.04 & 16.27 & 65 & 0.005 \\
\hline $\mathrm{PM}_{10}$ & 107.93 & 60.26 & 97.68 & 83.85 & 154 & 0.760 \\
\hline $\mathrm{PM}_{2.5}$ & 48.50 & 38.28 & 34.65 & 27.87 & 172 & 0.357 \\
\hline $\mathrm{SO}_{2}$ & 14.87 & 7.73 & 9.42 & 4.05 & 219 & 0.009 \\
\hline
\end{tabular}

a The dates of the two phases in study, both are 17 days. ${ }^{\mathrm{b}} \mathrm{W}$ means Wilcoxon statistic.

Table 3. The effects of lockdown on air pollutants and the AQI ${ }^{\mathrm{a}}$.

\begin{tabular}{cccccccc}
\hline & AQI & CO & $\mathbf{N O}_{\mathbf{2}}$ & $\mathbf{O}_{\mathbf{3}}$ & $\mathbf{P M}_{\mathbf{1 0}}$ & $\mathbf{P M}_{\mathbf{2 . 5}}$ & $\mathbf{S O}_{\mathbf{2}}$ \\
\hline$\beta_{\text {lockdown }} \mathrm{b}$ & 17.36 & $-0.20^{* *}$ & $-8.94^{* * *}$ & $8.41^{* * *}$ & 27.24 & 0.59 & -0.73 \\
Standard & 11.95 & 0.08 & 2.67 & 2.05 & 16.58 & 5.54 & 1.44 \\
error & 0.157 & 0.018 & 0.002 & 0.000 & 0.111 & 0.916 & 0.617 \\
$p$ & 0.876 & 0.946 & 0.969 & 0.962 & 0.900 & 0.935 & 0.904 \\
$\mathrm{R}^{2}$ & 68 & 68 & 68 & 68 & 68 & 68 & 68 \\
Observations & & & & & & 68 & \\
\hline
\end{tabular}

${ }^{* *} p<0.05 ;{ }^{* * *} p<0.001 .{ }^{a}$ The model has controlled weather variables (daily temperature, relative humidity, and wind speed), city fixed effect, and time fixed effect. ${ }^{b}$ Daily concentration change on average estimated by DID method during the lockdown period.

We collected the daily average pollutant concentrations between Shijiazhuang and Baoding before and during the lockdown policy. Drawing time series of the pollutants between Shijiazhuang and Baoding allowed us to observe whether the parallel trend assumption was satisfied in the DID model. Figure 1 shows that no systematic difference was observed before the lockdown period between the two cities. In addition, the $\mathrm{PM}_{2.5}$, $\mathrm{PM}_{10}$, and AQI parameters displayed small declines within 3 days but were followed by a very large increase after the implementation of the lockdown policy.

When we randomly moved up the start time of the lockdown policy in Shijiazhuang, we found that the estimate of $\beta$ gradually decreased and even became nonsignificant, reflecting that the lockdown policy indeed reduced the concentrations of related air pollutants, and our estimations were unlikely to be caused by other unobservable factors.

\subsection{Evaluation of the Short-Term Health Benefits during the Lockdown Period}

We evaluated the average daily excessive mortality of three clearly changed air pollutants after the DID analysis validation during the lockdown period. Among the estimates output by the DID model, the reductions in $\mathrm{NO}_{2}$ and $\mathrm{CO}$ could reduce the numbers of related deaths per day, while the effect of $\mathrm{O}_{3}$ was the opposite. The other pollutants did not change significantly during the lockdown period. According to Table 4 , the number of all-cause excess deaths avoided by $\mathrm{NO}_{2}$ during the lockdown period (17 days) was 14.63 (95\% CI: $11.25,18.00)$, while the number of all-cause excess deaths that occurred due to $\mathrm{O}_{3}$ was 8.89 (95\% CI: 6.77, 11.01). The numbers of deaths of cardiovascular diseases and respiratory diseases caused by the reduction in $\mathrm{NO}_{2}$ were also higher than the number of deaths caused by the increasing ozone concentration. Due to the lack of an exposure-response 
coefficient for all-cause and respiratory disease deaths due to $\mathrm{CO}$, we only evaluated the number of deaths due to cardiovascular disease. Additionally, we combined all-cause results of the three pollutants through adding respiratory mortality from CO. Overall, we estimated that 8.22 (95\% CI: 3.97, 12.49) all-cause deaths have been prevented during the lockdown period.
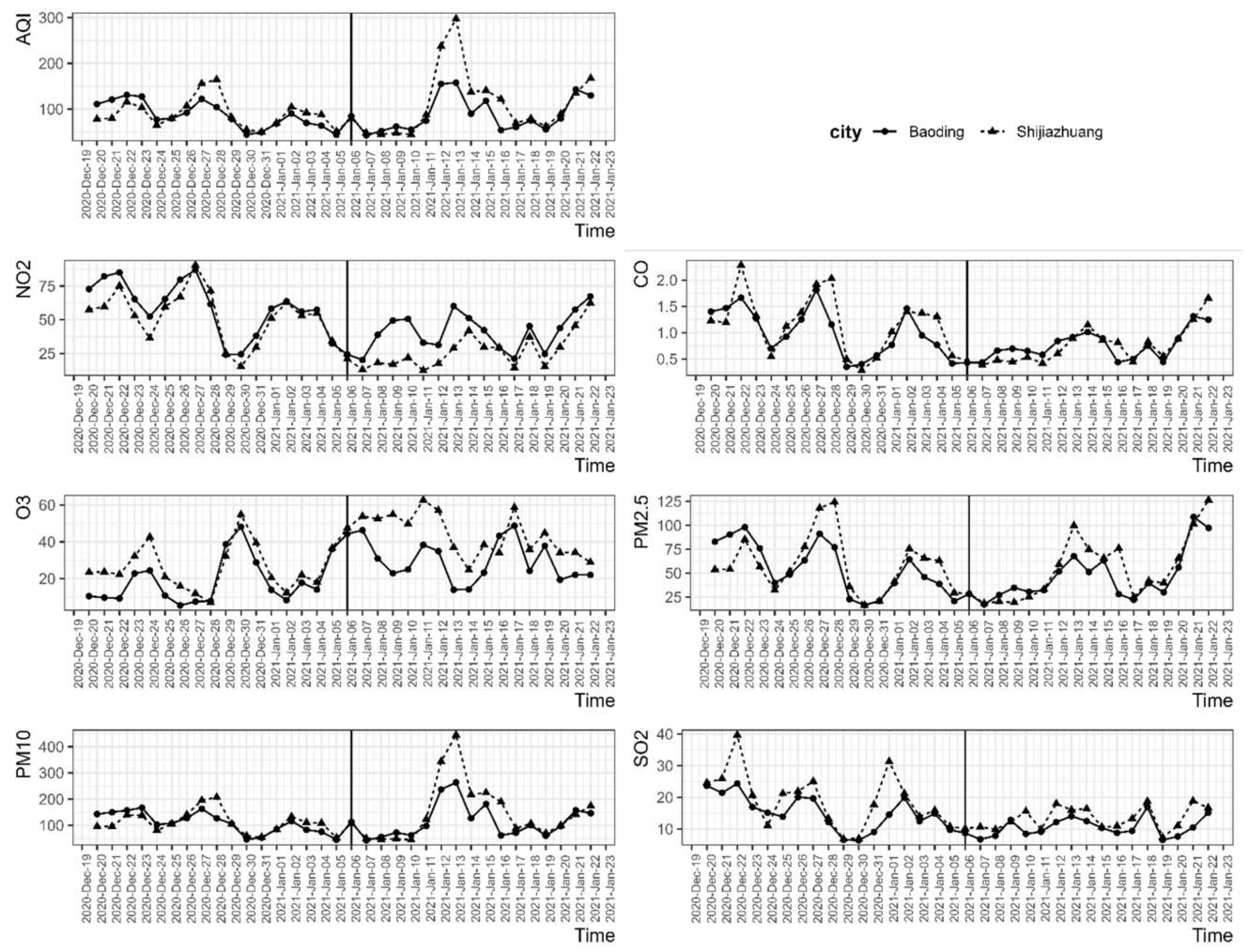

Figure 1. Time-series concentrations of air pollution in Shijiazhuang and Baoding. The solid black verticals are associated with the date of implementation of the lockdown policy.

Table 4. Number of deaths due to air pollutants change during the lockdown.

\begin{tabular}{|c|c|c|c|c|c|c|}
\hline & $\beta_{\text {lockdown }}$ & Cause of Death & Daily Deaths & $95 \% \mathrm{CI}$ & $\begin{array}{c}\text { Total Deaths } \\
\text { (17 days) }\end{array}$ & $95 \% \mathrm{CI}$ \\
\hline $\mathrm{NO}_{2}$ & -8.94 & All-cause deaths & $-0.86^{\mathrm{a}}$ & $-(0.66,1.06)$ & -14.63 & $-(11.25,18.00)$ \\
\hline \multirow[t]{2}{*}{$\mathrm{RC}^{\mathrm{c}}$} & $16.94 \%$ & Cardiovascular disease deaths & -0.35 & $-(0.24,0.46)$ & -5.93 & $-(4.05,7.80)$ \\
\hline & & Respiratory disease deaths & -0.12 & $-(0.07,0.16)$ & -2.00 & $-(1.26,2.74)$ \\
\hline $\mathrm{CO}$ & -0.20 & All-cause deaths & & & & \\
\hline $\mathrm{RC}$ & $16.95 \%$ & $\begin{array}{l}\text { Cardiovascular disease deaths } \\
\text { Respiratory disease deaths }\end{array}$ & -0.15 & $-(0.05,0.24)$ & -2.48 & $-(0.93,4.04)$ \\
\hline $\mathrm{O}_{3}$ & 8.41 & All-cause deaths & $+0.52^{b}$ & $+(0.40,0.65)$ & +8.89 & $+(6.77,11.01)$ \\
\hline \multirow[t]{3}{*}{$\mathrm{RC}$} & $32.80 \%$ & Cardiovascular disease deaths & +0.24 & $+(0.09,0.38)$ & +4.09 & $+(1.58,6.51)$ \\
\hline & & Respiratory disease deaths & +0.08 & $+(0.03,0.12)$ & +1.29 & $+(0.57,1.98)$ \\
\hline & amary & All-cause deaths & -0.48 & $-(0.23,0.73)$ & -8.22 & $-(3.97,12.49)$ \\
\hline
\end{tabular}

a The "-" indicates the number of deaths decreased due to reduced pollutant. ${ }^{\mathrm{b}}$ The " + " indicates the number of deaths increased due to increased pollutant. ${ }^{c} \mathrm{RC}$ : relative changes of air pollutants when comparing to the non-lockdown period.

\section{Discussion}

This is the first study in China to evaluate the health benefits of the lockdown policy through the case-control DID method. We found that the lockdown policy reduced the concentrations of $\mathrm{NO}_{2}$ and $\mathrm{CO}$ but worsened the $\mathrm{O}_{3}$ situation, reducing all-cause deaths by 11.36 cases. The decline in $\mathrm{SO}_{2}$ was more likely linked to the lockdown policy, as described in previous studies [24-26]. However, no significant changes in $\mathrm{SO}_{2}$ and $\mathrm{PM}$ were observed, 
and the DID method helped us to decrease the bias and led to the separation of the causal effects of the lockdown policy.

The sources of air pollution are complicated and asymmetrical. As primary pollutants, $\mathrm{CO}$ and $\mathrm{NO}_{2}$ were directly influenced by reduced emissions during the lockdown. $\mathrm{NO}_{2}$ is created when air is heated and, on average, occurs due to transportation (15-20\%) and fossil fuels in power plants (30-50\%) [27], whereas residential (43.9\%), transportation (29.4\%), and industrial (25.1\%) sources are the major sources of CO [28]. Given that residential heating was expected to increase during the lockdown period and given the insignificant changes in $\mathrm{PM}_{2.5}$ obtained herein (which is mainly generated by fossil fuel burning [29]), transportation played a crucial role in the relation between the air quality and lockdown policy. $\mathrm{O}_{3}$ is a secondary pollutant and is mainly generated by the photochemical reactions of nitrogen oxides and hydrocarbons from automobile exhaust under sunlight $[29,30]$. For $\mathrm{O}_{3}$, the seemingly abnormal increase may be derived from the decreased concentration of nitrogen oxides, which react with $\mathrm{O}_{3}$ [31]. The reductions in these primary pollutants slowed down their interactions with $\mathrm{O}_{3}$ and consequently elevated their levels; this effect was also observed in former studies [32,33].

PM represents the particle mass that enters the respiratory tract, and it includes both coarse and fine particles; the former is primarily produced by mechanical processes such as construction activities, road dust resuspension, and wind, whereas the latter originates mainly from combustion sources. We can see that $\mathrm{PM}_{2.5}$ and $\mathrm{PM}_{10}$ displayed short-term declines within three days after the lockdown policy was implemented, but the differences then decreased compared to Baoding, indicating that PM was not affected by the lockdown policy. A study in Austria showed a similar result: $\mathrm{PM}_{10}$ did not decline during the lockdown term, which might have been due to domestic heating [34]. It has been proven that coal combustion and PM are highly correlated [21]. Shijiazhuang strictly implemented the city lockdown policy from 6 January until 23 January. This period coincided with the heating period. According to the weather disaster warning information of the National Meteorological Center of CMA, a blue cold-wave warning was issued on 5 January [35]. Since the lockdown period in Shijiazhuang coincided with the heating period, fossil fuel heating may have caused a large amount of PM production. Research shows that during a cold wave in 2016, the cold wave increased the heating energy consumption by approximately $2.37 \%$ compared with 2014 [36]. Due to the lockdown policy, people may be more inclined to heating their home to a higher temperature than usual when they are at home [37]. All of the above factors may affect the PM level. Although the lockdown policy of the city reduced traffic flow, the PM level did not change significantly.

Using the DID method, we found that $\mathrm{SO}_{2}$ did not show a significant change due to the lockdown policy. A study in Wuhan, China, showed that during the lockdown period, atmospheric $\mathrm{SO}_{2}$ concentrations remained steady both annually and weekly [38]. This may be because industries are the most significant contributors, and smaller anthropogenic sources of $\mathrm{SO}_{2}$ emissions involve locomotives, ships, and vehicles with heavy equipment that burn fuel with a high sulfur content [39].

The overall impact of the COVID-19 epidemic is terrible, leading to death, disease, and economic loss. Many countries have had to implement lockdown policies [40]. In this study, we tentatively evaluated the health benefits of a lockdown policy, and the results indicate important implications for public health, even with the rise of $\mathrm{O}_{3}$. However, massive interventions were adopted during the lockdown period, and these interventions decreased air pollution but had high financial costs. Future research could explore these changes in air quality and the economic impacts of the lockdown and help leaders to implement rational policies in the future [41].

The reduction in traffic flow affected the level of air pollution, and we found that the $\mathrm{NO}_{2}$ concentration declined, while the AQI level had no significant change. Recent studies have shown that the key is to accelerate VOC emission reductions; this acceleration is expected to be achieved through the new emission standards for LDVs, and regional emission sources are expected to be simultaneously controlled to release the benefits of 
local traffic emission control, thereby improving the air quality [42]. The health benefits of the reduction in air pollution were proved significantly in a nationwide study [43]. A recent study also showed that the lockdown policy provided a good opportunity to test measures such as telecommuting, telemedicine, online business, and education [44]. These measures reduce people's travel and contact and have beneficial impacts associated with the improvement of air pollution; thus, these measures may promote the development of smart cities.

We used a relative case-control DID method to study the real effect of the COVID-19 lockdown policy on air pollution levels and the associated mortality burden in the city of Shijiazhuang. However, some limitations still exist. First, because Shijiazhuang was the only city with a COVID-19 outbreak during the study period, we could only include one city as an intervention group for this research, causing the external validity of the results to be limited to some extent. Second, we did not consider changes in residents' behaviors caused by the lockdown policy. The regulations implemented during the lockdown policy limited the behaviors of individuals, such as going outside. At the same time, the fact that we applied the annual mortality rate to infer the daily mortality is not very appropriate for our study period because the daily mortality is usually higher than the annual ones. Thus, bias in our results may exist in some way when estimating the impact of the health benefits of lockdown policies. Multicity studies and population activity models with empirical evaluations of policy effects are needed in the future. Third, although this study controlled for confounders that do not vary with time and are individual (city geography, city industrial capacity, etc.), it may not control all potential confounders that could lead to uncertainty.

\section{Conclusions}

Our study found that the average daily concentrations of $\mathrm{NO}_{2}$ and $\mathrm{CO}$ were reduced and the concentration of $\mathrm{O}_{3}$ was elevated under the impact of the lockdown policy. The excess number of deaths per day caused by these three significantly changing pollutants decreased. Lockdown policies, such as restrictions on public health and gatherings, are effective in alleviating air pollution and reducing health risks.

Supplementary Materials: The following are available online at https: / www.mdpi.com/article/ 10.3390 /ijerph18168702/s1, Table S1. Number of deaths due to $\mathrm{NO}_{2}$ change during the lockdown based two references.

Author Contributions: Conceptualization, G.L. and J.H.; methodology, Z.X. and R.C.; software, Z.X.; validation, G.L. and J.H.; formal analysis, Z.X.; resources, G.L.; data curation, Y.W.; writingoriginal draft preparation, Z.X.; writing-review and editing, Z.X., X.H. and W.H.; visualization, Z.X.; supervision, R.C.; project administration, R.C.; funding acquisition, G.L. All authors have read and agreed to the published version of the manuscript.

Funding: This research was funded by the SEE foundation.

Institutional Review Board Statement: Not applicable.

Informed Consent Statement: Not applicable.

Data Availability Statement: The weather data is gained from China National Environmental Monitoring Centre (CNEMC) and the meteorological conditions could be found online at https: / / www.ogimet.com accessed on 10 June 2021.

Acknowledgments: The authors thank the China National Environmental Monitoring Centre (CNEMC) and the Synop station for providing air pollution data and meteorological data. The study was supported by the SEE foundation. The funder had no role in study design, data collection and analysis, decision to publish, or preparation of the manuscript.

Conflicts of Interest: The authors declare no conflict of interest. 


\section{References}

1. World Health Organzation. Coronavirus Disease (COVID-19) Pandemic. Available online: https://www.who.int/emergencies/ diseases/novel-coronavirus-2019 (accessed on 21 April 2021).

2. Gandhi, M.; Yokoe, D.S.; Havlir, D.V. Asymptomatic Transmission, the Achilles' Heel of Current Strategies to Control COVID-19. N. Engl. J. Med. 2020, 382, 2158-2160. [CrossRef]

3. Naqvi, H.R.; Mutreja, G.; Shakeel, A.; Siddiqui, M.A. Spatio-temporal analysis of air quality and its relationship with major COVID-19 hotspot places in India. Remote Sens. Appl. 2021, 22, 100473.

4. Lau, H.; Khosrawipour, V.; Kocbach, P.; Mikolajczyk, A.; Schubert, J.; Bania, J.; Khosrawipour, T. The positive impact of lockdown in Wuhan on containing the COVID-19 outbreak in China. J. Travel Med. 2020, 27, taaa037. [CrossRef]

5. Bekbulat, B.; Apte, J.S.; Millet, D.B.; Robinson, A.L.; Wells, K.C.; Presto, A.A.; Marshall, J.D. Changes in criteria air pollution levels in the US before, during, and after COVID-19 stay-at-home orders: Evidence from regulatory monitors. Sci. Total Environ. 2021, 769, 144693. [CrossRef]

6. Achebak, H.; Petetin, H.; Quijal-Zamorano, M.; Bowdalo, D.; Pérez García-Pando, C.; Ballester, J. Trade-offs between short-term mortality attributable to NO2 and O3 changes during the COVID-19 lockdown across major Spanish cities. Environ. Pollut. 2021, 286, 117220. [CrossRef]

7. $\quad$ Lin, J.T.; Liu, M.Y.; Xin, J.Y.; Boersma, K.F.; Spurr, R.; Martin, R.; Zhang, Q. Influence of aerosols and surface reflectance on satellite $\mathrm{NO}_{2}$ retrieval: Seasonal and spatial characteristics and implications for $\mathrm{NO} x$ emission constraints. Atmos. Chem. Phys. 2015, 15, 11217-11241. [CrossRef]

8. Zhang, H.; Lin, Y.; Wei, S.; Loo, B.P.Y.; Lai, P.C.; Lam, Y.F.; Wan, L.; Li, Y. Global association between satellite-derived nitrogen dioxide (NO(2)) and lockdown policies under the COVID-19 pandemic. Sci. Total Environ. 2021, 761, 144148. [CrossRef]

9. Liu, Q.; Huang, J.; Guo, B.; Guo, X. Efficiency of Emission Control Measures on Particulate Matter-Related Health Impacts and Economic Cost during the 2014 Asia-Pacific Economic Cooperation Meeting in Beijing. Int. J. Environ. Res. Public Health 2017, 14, 19. [CrossRef] [PubMed]

10. Lin, H.; Liu, T.; Fang, F.; Xiao, J.; Zeng, W.; Li, X.; Guo, L.; Tian, L.; Schootman, M.; Stamatakis, K.A.; et al. Mortality benefits of vigorous air quality improvement interventions during the periods of APEC Blue and Parade Blue in Beijing, China. Environ. Pollut. 2017, 220 Pt A, 222-227. [CrossRef]

11. Giani, P.; Castruccio, S.; Anav, A.; Howard, D.; Hu, W.; Crippa, P. Short-term and long-term health impacts of air pollution reductions from COVID-19 lockdowns in China and Europe: A modelling study. Lancet Planet. Health 2020, 4, e474-e482. [CrossRef]

12. Venter, Z.S.; Aunan, K.; Chowdhury, S.; Lelieveld, J. Air pollution declines during COVID-19 lockdowns mitigate the global health burden. Environ. Res. 2021, 192, 110403. [CrossRef]

13. Chen, K.; Wang, M.; Huang, C.; Kinney, P.L.; Anastas, P.T. Air pollution reduction and mortality benefit during the COVID-19 outbreak in China. Lancet Planet. Health 2020, 4, e210-e212. [CrossRef]

14. Health Commission of Hebei Province. Shijiazhuang Released 10 Measures for Community Prevention and Control: NonResidents Strictly Control Entry and Exit. Available online: http://www.hebwsjs.gov.cn/html/sxdt/20210106/375242.html (accessed on 23 February 2021).

15. Health Commission of Hebei Province. Starting Today. Shijiazhuang Implements District and Hierarchical Control. 2021. Available online: http:/ /www.hebwsjs.gov.cn/html/sxdt/20210123/375841.html (accessed on 23 February 2021).

16. Available online: http:/ / tjj.sjz.gov.cn/col/1584345215439/2020/04/13/1587111783229.html (accessed on 23 February 2021).

17. Ma, W.; Zeng, W.; Zhou, M.; Wang, L.; Rutherford, S.; Lin, H.; Liu, T.; Zhang, Y.; Xiao, J.; Zhang, Y.; et al. The short-term effect of heat waves on mortality and its modifiers in China: An analysis from 66 communities. Environ. Int. 2015, 75, 103-109. [CrossRef]

18. Chen, R.; Yin, P.; Meng, X.; Wang, L.; Liu, C.; Niu, Y.; Lin, Z.; Liu, Y.; Liu, J.; Qi, J.; et al. Associations Between Ambient Nitrogen Dioxide and Daily Cause-specific Mortality: Evidence from 272 Chinese Cities. Epidemiology 2018, 29, 482-489. [CrossRef]

19. Chen, K.; Breitner, S.; Wolf, K.; Stafoggia, M.; Sera, F.; Vicedo-Cabrera, A.M.; Guo, Y.; Tong, S.; Lavigne, E.; Matus, P.; et al. Ambient carbon monoxide and daily mortality: A global time-series study in 337 cities. Lancet Planet Health 2021, 5, e191-e199. [CrossRef]

20. Wang, X.; Mauzerall, D.L. Evaluating impacts of air pollution in China on public health: Implications for future air pollution and energy policies. Atmos. Environ. 2006, 40, 1706-1721. [CrossRef]

21. Li, J.; Zhang, X.; Li, G.; Wang, L.; Yin, P.; Zhou, M. Short-term effects of ambient nitrogen dioxide on years of life lost in 48 major Chinese cities, 2013-2017. Chemosphere 2021, 263, 127887.

22. Liu, C.; Yin, P.; Chen, R.; Meng, X.; Wang, L.; Niu, Y.; Lin, Z.; Liu, Y.; Liu, J.; Qi, J.; et al. Ambient carbon monoxide and cardiovascular mortality: A nationwide time-series analysis in 272 cities in China. Lancet Planet. Health 2018, 2, e12-e18. [CrossRef]

23. Yan, M.; Liu, Z.; Liu, X.; Duan, H.; Li, T. Meta-analysis of the Chinese studies of the association between ambient ozone and mortality. Chemosphere 2013, 93, 899-905. [CrossRef] [PubMed]

24. Liu, F.; Wang, M.; Zheng, M. Effects of COVID-19 lockdown on global air quality and health. Sci. Total Environ. 2021, 755, 142533. [CrossRef] 
25. Chen, G.; Tao, J.; Wang, J.; Dong, M.; Li, X.; Sun, X.; Cheng, S.; Fan, J.; Ye, Y.; Xiao, J.; et al. Reduction of air pollutants and associated mortality during and after the COVID-19 lockdown in China: Impacts and implications. Environ. Res. 2021, 200, 111457. [CrossRef]

26. Bao, R.; Zhang, A. Does lockdown reduce air pollution? Evidence from 44 cities in northern China. Sci. Total Environ. 2020, 731 , 139052. [CrossRef]

27. Rohde, R.A.; Muller, R.A. Air Pollution in China: Mapping of Concentrations and Sources. PLoS ONE 2015, 10, e0135749.

28. Liu, X.Y.; He, K.B.; Zhang, Q.; Lu, Z.F.; Wang, S.W.; Zhang, Y.X.; Streets, D.G. Analysis of the origins of black carbon and carbon monoxide transported to Beijing, Tianjin, and Hebei in China. Sci. Total Environ. 2019, 653, 1364-1376. [CrossRef]

29. Scovronick, N.; Wilkinson, P. Health impacts of liquid biofuel production and use: A review. Glob. Environ. Chang. 2014, 24, 155-164. [CrossRef]

30. Zeng, P.; Lyu, X.P.; Guo, H.; Cheng, H.R.; Jiang, F.; Pan, W.Z.; Wang, Z.W.; Liang, S.W.; Hu, Y.Q. Causes of ozone pollution in summer in Wuhan, Central China. Environ. Pollut 2018, 241, 852-861. [CrossRef]

31. Marr, L.C.; Harley, R.A. Spectral analysis of weekday-weekend differences in ambient ozone, nitrogen oxide, and non-methane hydrocarbon time series in California. Atmos. Environ. 2002, 36, 2327-2335. [CrossRef]

32. Sicard, P.; De Marco, A.; Agathokleous, E.; Feng, Z.; Xu, X.; Paoletti, E.; Rodriguez, J.J.D.; Calatayud, V. Amplified ozone pollution in cities during the COVID-19 lockdown. Sci. Total Environ. 2020, 735, 139542. [CrossRef]

33. Tobías, A.; Carnerero, C.; Reche, C.; Massagué, J.; Via, M.; Minguillón, M.C.; Alastuey, A.; Querol, X. Changes in air quality during the lockdown in Barcelona (Spain) one month into the SARS-CoV-2 epidemic. Sci. Total Environ. 2020, 726, 138540. [CrossRef] [PubMed]

34. Lovrić, M.; Pavlović, K.; Vuković, M.; Grange, S.K.; Haberl, M.; Kern, R. Understanding the true effects of the COVID-19 lockdown on air pollution by means of machine learning. Environ. Pollut. 2021, 274, 115900. [CrossRef] [PubMed]

35. National Meteorological Center. Blue Alert for Cold Wave. Available online: https://baijiahao.baidu.com/s?id=16879932453739 28406\&wfr=spider\&for $=$ pc (accessed on 23 February 2021).

36. Jiang, D.; Xiao, W.; Wang, J.; Wang, H.; Zhao, Y.; Li, B.; Zhou, P. Evaluation of the effects of one cold wave on heating energy consumption in different regions of northern China. Energy 2018, 142, 331-338. [CrossRef]

37. Yan, L.; Li, J.; Liu, M.; Hu, M.; Xu, Z.; Xue, K. Heating behavior using household air-conditioners during the COVID-19 lockdown in Wuhan: An exploratory and comparative study. Build. Environ. 2021, 195, 107731. [CrossRef]

38. Pei, Z.; Han, G.; Ma, X.; Su, H.; Gong, W. Response of major air pollutants to COVID-19 lockdowns in China. Sci. Total Environ. 2020, 743, 140879. [CrossRef] [PubMed]

39. Tian, X.; An, C.; Chen, Z.; Tian, Z. Assessing the impact of COVID-19 pandemic on urban transportation and air quality in Canada. Sci. Total Environ. 2021, 765, 144270. [CrossRef]

40. Rodríguez-Urrego, D.; Rodríguez-Urrego, L. Air quality during the COVID-19: PM(2.5) analysis in the 50 most polluted capital cities in the world. Environ. Pollut. 2020, 266 Pt 1, 115042. [CrossRef]

41. Bherwani, H.; Nair, M.; Musugu, K.; Gautam, S.; Gupta, A.; Kapley, A.; Kumar, R. Valuation of air pollution externalities: Comparative assessment of economic damage and emission reduction under COVID-19 lockdown. Air Qual. Atmos. Health 2020, 13, 683-694. [CrossRef]

42. Lv, Z.; Wang, X.; Deng, F.; Ying, Q.; Archibald, A.T.; Jones, R.L.; Ding, Y.; Cheng, Y.; Fu, M.; Liu, Y.; et al. Source-Receptor Relationship Revealed by the Halted Traffic and Aggravated Haze in Beijing during the COVID-19 Lockdown. Environ. Sci. Technol. 2020, 54, 15660-15670. [CrossRef] [PubMed]

43. Huang, J.; Pan, X.; Guo, X.; Li, G. Health impact of China's Air Pollution Prevention and Control Action Plan: An analysis of national air quality monitoring and mortality data. Lancet Planet. Health 2018, 2, e313-e323. [CrossRef]

44. Kunzmann, K.R. Smart Cities After COVID-19: Ten Narratives. disP-Plan. Rev. 2020, 56, 20-31. [CrossRef] 